\title{
Transmission of Vibration from Tool Handle to Wrist and to Head
}

\author{
JUKKA STARCK, JUSSI PEKKARINEN AND LIU CHANG CHUN \\ Institute of Occupational Health, Laajaniityntie 1, SF-01620 Vantaa, Finland
}

Received for publication May 22, 1989

\begin{abstract}
Summary: Transmission of vibration from the handle of the tool to the handarm system was investigated by measuring vibration in pairs from the source and from the wrist and head. The frequency response function was applied to describe the transmission properties. The measurements were taken at work places to evaluate the effect of different work-related factors on the transmission. Laboratory measurements were conducted to evaluate the effect of different grip forces and the use of protective gloves on the transmission. The field measurements comprised five different groups of workers whose exposure to vibration was evaluated and whose observed symptoms of vibration-induced white finger (VWF) was compared to the predicted ones based on the exposure data and on ISO 5349. The comparison of the prevalence data was in good agreement for the forest workers. The ISO method seemed to underestimate the genesis of VWF in workers who had to use high grip forces and for whom the vibration comprised high values of impulsiveness. The present results suggest that the frequency response function as independent of the input signal may thus describe factors important to the transmission of vibration.
\end{abstract}

Key words: forest work - impulsiveness - pedestal grinding - shipyard work - vibration disease

\section{Introduction}

At present 15 different limits have been proposed for the general risk assessment of vibration (Griffin, 1982). None of the vibration limits can be considered to comprise a complete and unambiguous limit for risk assessment. However, technical measurements and analysis of the vibration signal are well established, but the evaluation of important factors in risk assessment has been less well understood. The discrepancies between existing doseresponse relationships illustrate the need for further studies on hand-arm vibration. Digital high-speed measuring techniques and computer-based data processing give new possibilities for the evaluation of dose-response relationships.

The hand-arm vibration syndrome de- pends, in addition to the level and duration of vibration acceleration, on factors such as handling the tool, dominant frequency of vibration, and on the body constitution (ISO 5349, 1986). Protective gloves are now used to reduce exposure to the vibration generated by hand-arm power tools (Rens et al. 1987). On the other hand, workers also wear gloves as insulation against heat or cold and to protect against mechanical damage. Even if the vibration attenuation is low, the overall protective effect may be valuable. In laboratory experiments, whole body vibration has caused changes in hearing sensitivity which could be caused either directly by vibration transmission to the head bones or indirectly by stimulation of the central nervous system (Okada et al. 1972; Manninen and Ekblom, 1984). 
The role of hand-arm vibration in the genesis of hearing damage has remained obscure (Starck et al. 1988).

The present study was aimed to compare the observed and predicted symptoms and signs of vibration-induced white finger (VWF), relate the findings to physical parameters obtained in the laboratory and field measurements at working places, paying special attention to the transmission of vibration from the hand-arm system to the head of the operator.

\section{Materials and Methods}

\section{Laboratory measurements}

An electrodynamic vibration exciter (B \& K 4813) was used to vibrate the handle of the tool which was constructed to simulate a hand-held power tool (Fig. 1). The shaker was excited by white noise at frequencies ranging from $10 \mathrm{~Hz}$ to $630 \mathrm{~Hz}$ for the handle-wrist transmission test, and

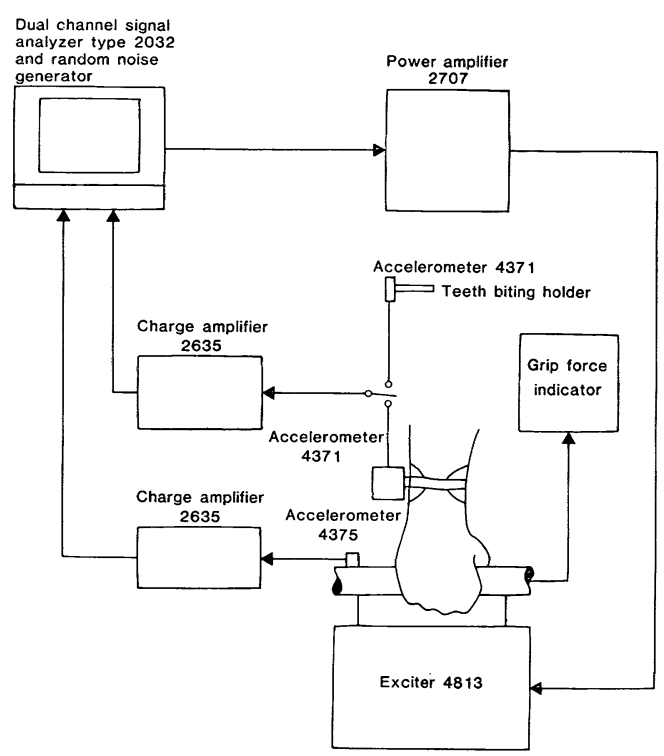

Fig. 1. Block diagram of vibration exciter and analyzing equipment in laboratory measurements
$10 \mathrm{~Hz}$ to $60 \mathrm{~Hz}$ for the handle-head transmission test because the absorption of the vibration frequency above $60 \mathrm{~Hz}$ was higher than the dynamic range of the measuring equipment. The white noise excitation signal was emitted by a random noise generator built in the dual channel signal analyzer (B \& K 2032) and amplified by a power amplifier (B \& K 2707 and $B \& \mathrm{~K} 2706)$. The acceleration was constant at $130 \mathrm{~dB} \pm 1 \mathrm{~dB}$ (ref. $10^{-6} \mathrm{~m}$ $/ \mathrm{s}^{2}$ ). The acceleration of the handle was recorded by an accelerometer (B \& K 4375 , $2.6 \mathrm{~g}$ ) attached to the handle of the shaker.

The acceleration of the wrist was measured by an accelerometer (B \& K 4371) weighting $13.2 \mathrm{~g}$ and mounted on a special plexiglass form (Färkkilä et al. 1978). The plexiglass form was supported by the styloid process in the wrist to keep the accelerometer parallel to the wrist. The measuring system was held in place by a metal ring for screw tightening. The total weight of the devices fixed on the wrist was $34 \mathrm{~g}$. The acceleration in the head of the subject was measured by an accelerometer (B \& K 4371) fixed between the jaws by a biting holder to measure the vibration transmitted to the bones of the head. The total weight of the biting holder and accelerometer was $33 \mathrm{~g}$. The two simultaneous acceleration signals from the handle and from the wrist or head were amplified by two charge amplifiers (B \& K 2635) and the frequency response function (FRF) was analyzed by a dual channel signal analyser (B \& K 2032).

The transmission loss provided by the vibration protection glove, type Winter Fireball 23-491 weight $100 \mathrm{~g}$, was determined by the difference between the frequency response functions with and without gloves.

The handle mounted to the shaker consisted of two metal bars with strain gauges (diameter $20 \mathrm{~mm}$ ) (Färkkilä et al. 1979). The subject kept his grip force 
constant by watching the grip force indicator. The hand grip force indicator was calibrated by loading the handle with $20 \mathrm{~N}$, $40 \mathrm{~N}$ and $60 \mathrm{~N}$ static forces obtained from known masses. The influence of different grip forces $(20,40$ and $60 \mathrm{~N})$ on the transmission of vibration was measured, while the acceleration level was kept constant $(130 \mathrm{~dB})$. The study involved five subjects. During the test the subjects were sitting with their upper arm $30^{\circ}$ below the horizontal level and the elbow joint at an angle of $120^{\circ}$. All the measurements were repeated three times.

\section{Field measurements}

\section{Subjects}

The study was comprised of five groups of male workers exposed to vibration from different types of tools. A longitudinal study among forest workers was conducted from $1972(\mathrm{~N}=118)$ to $1986(\mathrm{~N}=199)$ on persons who had used chain saws for at least three consecutive years for a minimum of 500 hours a year. The investigation was done in connection with a compulsory health examination. In addition to the study on all forest workers, the symptoms of vibration syndrome were evaluated among a subgroup of forest workers who participated in the study for the entire follow-up period (Pyykkö et al. 1986).

In the cross sectional studies 12 pedestal grinders, 16 stone workers, 171 shipyard workers and 5 platers were investigated. They were selected to represent different exposures to vibration and different of VWF symptoms. The pedestal grinders were exposed to vibration with high impulsiveness which was found to cause symptoms after a latency period of about one year. The stone workers and platers were exposed to extremely asymmetrical hand vibration, and the shipyard workers were exposed to $\mathrm{vi}$ bration caused by hand-held power tools used in metal works.

During the course of the medical examination, each subject completed a questionnaire on his state of health use of different power tools, use of medications, and symptoms of vibration syndrome. A medical history was recorded and particular attention was paid to symptoms and signs of vibration syndrome.

\section{Tools}

Vibration measurements were obtained with three different generations of chain saws to calculate the total exposure of forest workers in the follow-up study since 1972. The first generation chain saw was not equipped with any antivibration elements. The second and third generation chain saws were selected to represent chain saws in professional use in the 1970s and 1980s respectively (Starck, 1984).

Pedestal grinding was used in a foundry for cleaning small castings by hand. The vibration of two different types of grinding wheels was measured. One wheel was made of corundum and the other of zirconium corundum with a bond material that was clearly harder than in the corundum wheel. Other constructional properties were equal in both of the wheels. The corundum wheel had been used for several years and had not caused any symptoms of VWF in any of the grinders, whereas the zirconium corundum wheel was found to be very hazardous since all the workers had contracted the syndrome within one year after changing to this wheel (Starck et al. 1983).

Pneumatic hammers were used by the stone workers who were exposed to extremely asymmetric vibration, since their left hand was in contact with the chisel head and the right hand with the barrel of the hammer. The vibration measurements were taken from an Atlas Copco BHV 22 hammer which weighted $1.4 \mathrm{~kg}$ and had an $83 \mathrm{~Hz}$ strike frequency (Färkkilä et al. 1978). 
Altogether, 171 shipyard workers used different kinds of pneumatic power tools regularly in their work. The tools included grinding machines, scaling and riveting hammers. The average total operation time was $2 \mathrm{~h}$ a day in the shipyard. The vibration measurements were taken from 48 different hand held power tools.

Exposure to vibration among platers in the manufacture of different kinds of blades was measured when the blades were straightened after hardening. The straigh tening took place by hammering the blade with a hammer in the right hand, and holding the blade in place with the left hand which was exposed to extremely high vibration impulses from the blade.

\section{Measurement at wrist}

The transmission of vibration from the handle of the tool depends on factors whose effect can not always be estimated. To evaluate the transmission of vibration to the finger-hand-arm area, the vibration was also measured simultaneously also from the wrist. For the measurements, an accelerometer was fastened to a plastic plate which was adjusted to fit against the styloid process of the wrist and held there with a tightener and a plastic support (Färkkilä et al. 1978).

\section{Weighted acceleration ISO 5349 method}

Vibration measurements were taken at work places according to the ISO 5349 standard which allows the measurement of frequency-weighted acceleration (ISO 5349 , 1986). Different daily operation times were required to calculate the timeweighted daily exposure (equation 1).

$$
\begin{aligned}
\mathrm{a}_{\mathrm{w} 4 \mathrm{~h}}= & \mathrm{a}_{\mathrm{w}}(\mathrm{T} / 4)^{1 / 2} \\
\mathrm{a}_{\mathrm{w} 4 \mathrm{~h}}= & \text { energy equivalent acceleration } \\
& \text { for a period of } 4 \mathrm{~h} / \text { day } \\
\mathrm{a}_{\mathrm{w}}= & \text { energy equivalent acceleration } \\
& \text { for a period of } \mathrm{T} \mathrm{h} / \text { day } \\
\mathrm{T}= & \sum \mathrm{t}_{\mathrm{i}}, \text { total daily exposure time } \\
& \text { with different exposure periods, } \mathrm{t}_{\mathrm{i}}
\end{aligned}
$$

In addition to weighted vibration, unweighted vibration was also analyzed from the tool handle and from the wrist.

\section{Risk assessment}

The ISO 5349 standard provides a method for estimating the risk of vibrationinduced white finger based on the frequency and time weighted acceleration (equation 1). The risk assessment relates to the regular daily exposure and allows the calculation of the time for episodes of finger blanching to occur in 10 to $50 \%$ of the exposed persons (ISO 5349, 1986) (equation 2).

$$
\mathrm{c}=\left(\frac{\mathrm{a}_{\mathrm{w} 4 \mathrm{~h}} \times \mathrm{T}_{\mathrm{f}}}{95}\right) 2 \times 100
$$

c $=$ percentile of exposed persons expected to show vascular disorders $(10 \% \leq \mathrm{c} \leq 50 \%)$

$T_{\mathrm{f}}=$ exposure time before finger blanch ing occured in years $\left(1 \leqq T_{\mathrm{f}} \leqq 25\right)$

Equation 2 was used to calculate expected latencies and prevalences based on the vibration measurements and on the occupational histories.

\section{High frequency analyses}

Frequency analysis was done by applying the Fourier transform technique (FFT) to the samples in the time domain. Each block contained 5000 samples which were windowed with a Hanning window to reduce spectral leakage. The spectra were first averaged over 5 to 10 blocks for each worker and then over several workers in each occupational group. The spectra were calculated in two frequency areas; below $1500 \mathrm{~Hz}$ corresponding to the ISO 5349 frequency weighting area, and for $1500-10000 \mathrm{~Hz}$ corresponding to the high frequency area of vibration acceleration. The transmission of vibration was evaluated by analyzing the frequency response function for different operations with hand-held power tools between the 
source of vibration and the wrist (Pekkarinen and Starck, 1986).

\section{Impulsiveness}

Impulsiveness of vibration was defined as the difference between the peak and RMS levels of vibration (Starck, 1984). The difference is also known as the crest factor of the signal. It is independent of the signal level but describes the waveform characteristics (IEC 651. 1979). Vibration with the time-varying crest factor was analyzed with a cumulative distribution function of the crest factor. A parameter called impulse index $I_{1}$ was selected for numerical comparison, which corresponds to a one per cent probability of measurement duration when a certain average crest factor is exceeded (Starck, 1984).

\section{Results}

\section{Laboratory measurements}

The coherence was inspected during measurements to find any non-linearities in the hand-wrist-arm transmission system. Generally the coherence function had a value higher than 0.8 which indicates that the measurement system is essentially linear; but at some frequencies a sharp decrease of coherence occurred, the reason for which will be discussed later. Fig. $2 \mathrm{a}$ and $\mathrm{b}$ shows the typical attenuation curves (FRF) with and without gloves for a test subject. The largest deviations observed between the three tests taken for a test subject varied between $2-5 \mathrm{~dB}$ without gloves and 2-7 dB with gloves (Fig. 2).

Fig. 3 shows the mean FRFs for five subjects when different grip forces were used without gloves. The attenuation of the vibration in the wrist was $12.5 \mathrm{~dB}$ at a frequency of $40 \mathrm{~Hz}$ when the grip force was $20 \mathrm{~N}$. The attenuation increased when the frequency of vibration increased. At

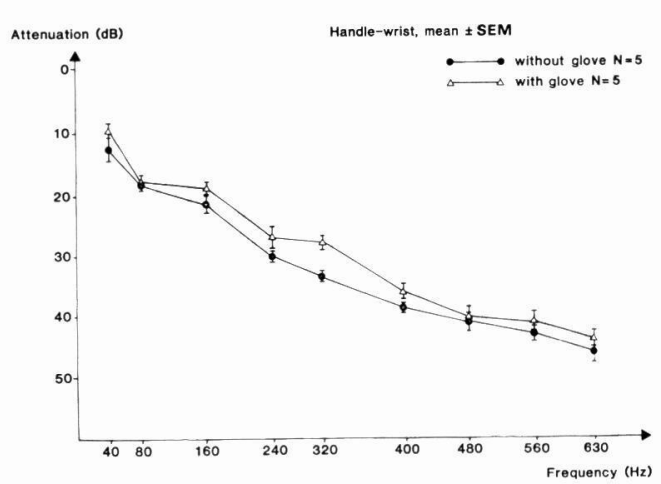

a) the wrist, grip force $20 \mathrm{~N}$

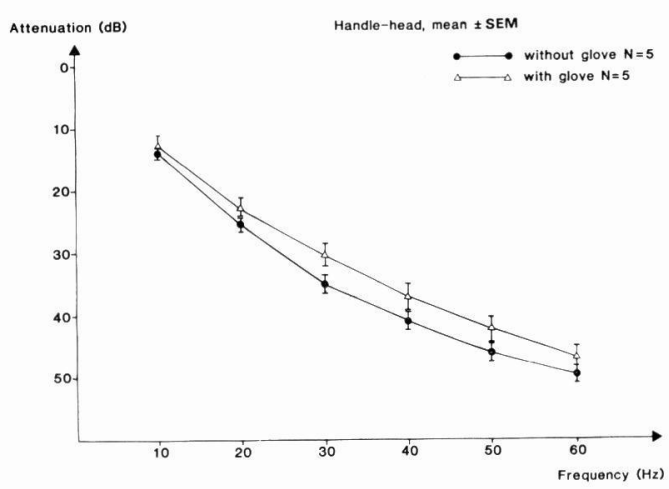

b) the head, grip force $40 \mathrm{~N}$

Fig. 2. Effect of gloves on the attenuation between the handle and a) the wrist, grip force $20 \mathrm{~N} \mathrm{~b}$ ) the hand, grip force $40 \mathrm{~N}$ Average and standard error of mean are displayed, $\mathrm{N}=5$

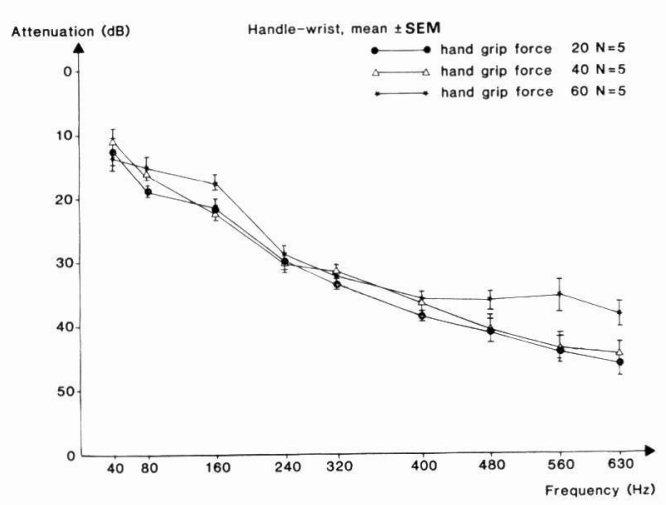

Fig. 3. Effect of hand grip force on the attenuation between the handle and wrist 
a frequency of $630 \mathrm{~Hz}$ the attenuation was $46 \mathrm{~dB}$ in the wrist when the hand grip force was $20 \mathrm{~N}$.

Fig. 3 also indicates that the attenuation of vibration in the wrist decreased as the grip force increased. Below $400 \mathrm{~Hz}$ the differences among the three curves are 2 to $5 \mathrm{~dB}$. Above $400 \mathrm{~Hz}$ the difference between the curve with $20 \mathrm{~N}$ and the curve with $40 \mathrm{~N}$ is only 0.5 to $2 \mathrm{~dB}$. The difference between the curve with $20 \mathrm{~N}$ and the curve with $60 \mathrm{~N}$ is 3 to $8 \mathrm{~dB}$.

The gloves increased the transmission of vibration to the wrist at all frequencies from 10 to $630 \mathrm{~Hz}$ when hand grip forces were $20 \mathrm{~N}$ and $40 \mathrm{~N}$.

The attenuation of vibration in the head without gloves was $24 \mathrm{~dB}$ at $10 \mathrm{~Hz}$ and $60 \mathrm{~dB}$ at $60 \mathrm{~Hz}$ (Fig. 2). With increasing frequency the attenuation of vibration to the head increased. When the subjects wore gloves, the transmission of vibration was 1 to $4 \mathrm{~dB}$ more than without gloves at the range of 10 to $60 \mathrm{~Hz}$.

\section{Field measurements}

\section{Chain saws}

Since 1972 the technical properties of chain saws have improved considerably. This has had a clear influence on the vibration and on the outbreak of different symptoms of vibration disease. This improvement has been the main cause of the $90 \%$ decrease in the weighted acceleration that occurred during the course of exposure to chain saw vibration.

The lighter weight of the chain saws, together with the attenuation of high frequency components in vibration acceleration, has affected the transmission of vibration from the handle of the chain saw to the wrist. The decreased impulsiveness is related also to the lowering of high frequencies in the course of chain saw generations.

\section{Stone workers}

The stone workers were exposed to extremely asymmetric vibration, as the ratio of the acceleration between vibration transmitted to left and right hands was nearly 1000 . The ratio between the corresponding wrists was only four.

\section{Pedestal grinding}

The weighted acceleration and the $1 / 3$ octave spectra were equal $\left(20 \mathrm{~m} / \mathrm{s}^{2}\right)$ when cleaning castings with old corundum and new zirconium corundum grinding wheels. The impulsiveness of the vibration generated was $18 \mathrm{~dB}$ and $21 \mathrm{~dB}$, respectively, for both of the wheels.

\section{Shipyard workers}

The measurements were taken in a shipyard assembly hall with the pneumatic power tools most commonly used by the platers, welders and grinders. The weighted acceleration for the different grinding machines varied between 0.4 and $6 \mathrm{~m} / \mathrm{s}^{2}$. Pneumatic hammers clearly generated higher weighted accelerations vary ing from 6 to $300 \mathrm{~m} / \mathrm{s}^{2}$.

\section{Platers}

The vibration was measured from three different circular and rectangular blades with five repetitions for each blade. The average peak levels were $8.8 \mathrm{~km} / \mathrm{s}^{2}$ for circular blades $(\phi 1000-1800 \mathrm{~mm})$ and 29 $\mathrm{km} / \mathrm{s}^{2}$ for rectangular blades (length 1165 $2750 \mathrm{~mm}$, width $155-200 \mathrm{~mm}$, thickness 18 $40 \mathrm{~mm}$ ). The weighted $\mathrm{rms}$ accelerations were correspondingly $14 \mathrm{~m} / \mathrm{s}^{2}$ and $355 \mathrm{~m}$ $/ \mathrm{s}^{2}$. Impulsiveness was equal for both blade types.

\section{Comparison of the results}

Acceleration measurements were taken simultaneously from the source of vibration and the corresponding wrist. The transmission of vibration to the wrist is influenced by work-related factors in addition to vibration characteristics of the 


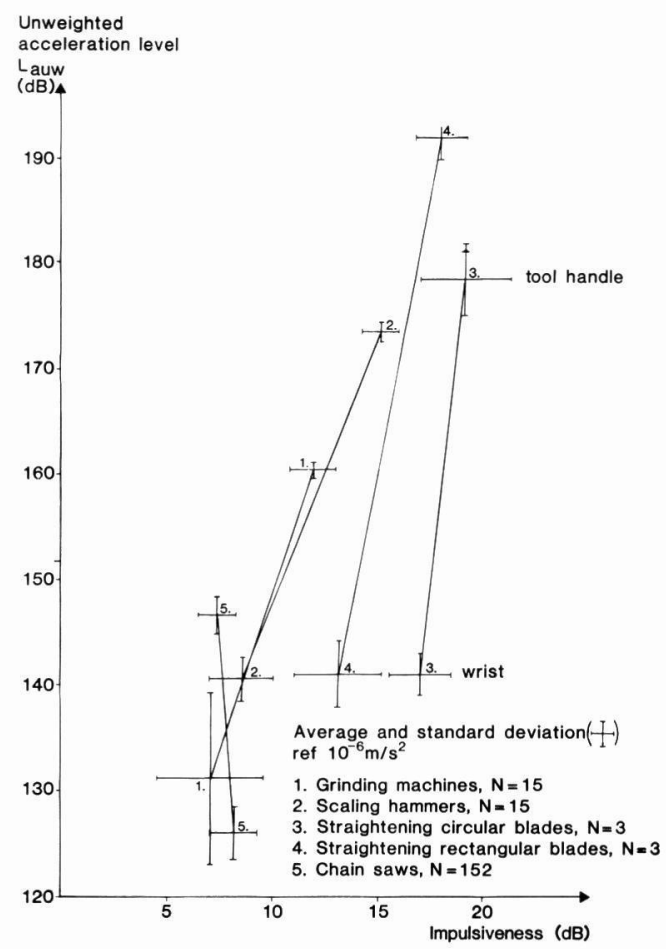

Fig. 4. Unweighted acceleration rms levels $(\mathrm{dB})$ and impulsiveness of vibration at the source of vibration (upper number) and corresponding wrist (lower number), average and standard deviation $(\mid)$, ref $10^{-6}$ $\mathrm{m} / \mathrm{s}^{2}$

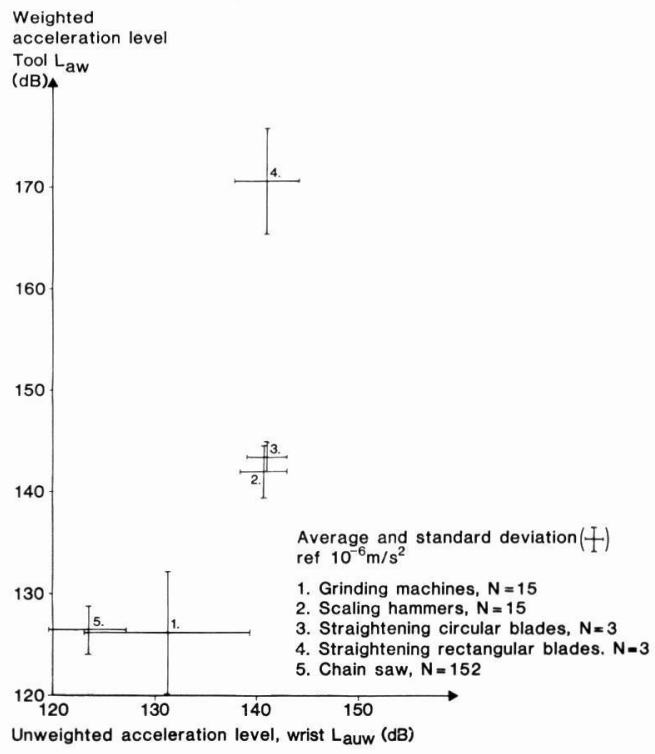

Fig. 5. Weighted acceleration levels (dB) at the source of vibration in comparison to the unweighted acceleration levels $(\mathrm{dB})$ at the wrist, average and standard deviation (l), ref $10^{-6} \mathrm{~m} / \mathrm{s}^{2}$
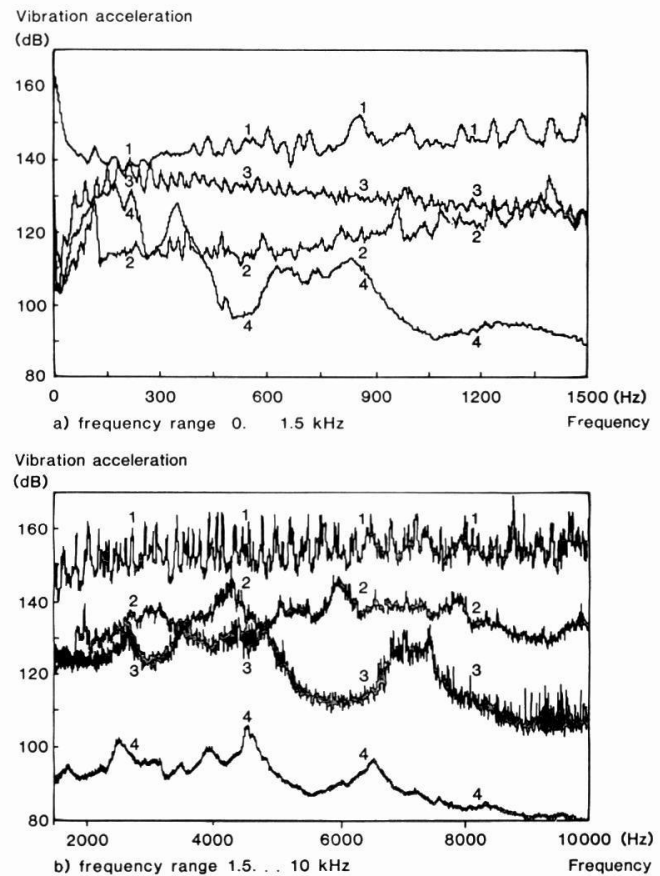

Fig. 6. Power spectra for vibration acceleration, ref $10^{-6} \mathrm{~m} / \mathrm{s}^{2}$
a) frequency area $0-1.5 \mathrm{kHz}$
b) frequency area $1.5-10 \mathrm{kHz}$
1. straightening of blades
2. vertical grinding machine
3. pedestal grinding
4. chain saw

source. Figure 4 shows that different exposures to hand-arm vibration have different transmission properties. RMS acceleration levels and impulsiveness of vibration are the highest when straightening blades by hammering. The lowest acceleration and impulsiveness was measured from the chain saws. The results measured from the hand held power tools used at the shipyard were between the previous values.

The frequency-weighted acceleration at the source is nearly equal to the unweighted acceleration at the wrist (Fig. 5). Transmission of vibration and its absorption to the finger-palm area seems to be independent of the level of acceleration. 


\section{Frequency analysis}

Straightening of blades generated vibration acceleration with the highest level and frequency content. The vibration spectrum had about the same level up to $10 \mathrm{kHz}$. The lowest vibration level and frequency content were analyzed for chain saws.

The slope of the frequency response functions are about equal in all measurements below $750 \mathrm{~Hz}$. At high frequencies, the frequency response function for chain saw operators is about $10-20 \mathrm{~dB}$ higher than for other workers (Fig. 7).

\section{Prevalence of $V W F$}

Expected latency and prevalence data were compared to those observed among different groups of workers (Table 1). The comparison showed best agreement for forest workers. The comparison was most discrepant for pedestal grinders,

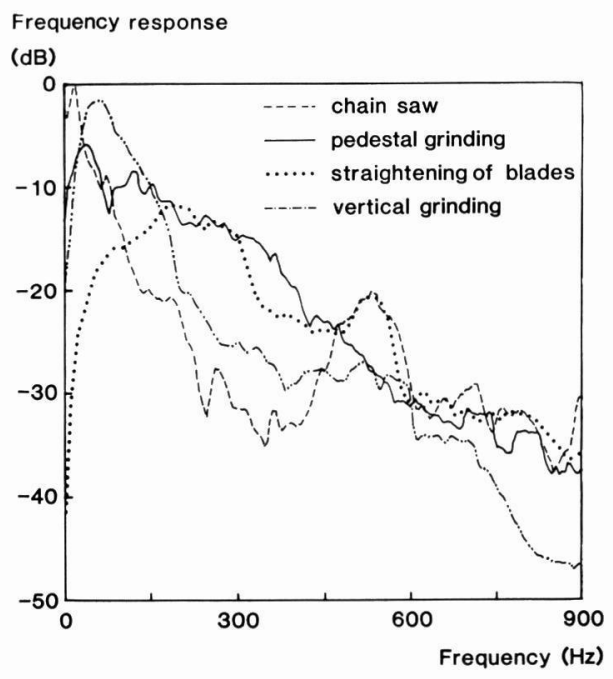

Fig. 7. Frequency response functions analyzed between source and wrist

TABLE 1

Expected latency and prevalence of VWF assessed according to ISO 5349 in comparison with the observed latency and prevalence

\begin{tabular}{|c|c|c|c|c|c|c|c|c|c|}
\hline \multirow{2}{*}{ Subject/tool } & \multirow{2}{*}{$\mathrm{N}$} & \multicolumn{2}{|c|}{ Vibration } & \multirow{2}{*}{$\begin{array}{l}\mathrm{a}_{\mathrm{w}} 4 \mathrm{~h} \\
\mathrm{~m} / \mathrm{s}^{2}\end{array}$} & \multirow{2}{*}{$\begin{array}{l}\text { Impulsive- } \\
\text { ness } 1 \mathrm{~dB}\end{array}$} & \multicolumn{2}{|c|}{$\begin{array}{l}\text { Expected latency } \\
\text { at prevalence }\end{array}$} & \multicolumn{2}{|c|}{$\begin{array}{l}\text { Observed latency } \\
\text { prevalence }\end{array}$} \\
\hline & & $\begin{array}{c}\mathrm{a}_{\mathrm{w}} \\
\mathrm{m} / \mathrm{s}^{2}\end{array}$ & $\begin{array}{c}\mathrm{T} \\
\mathrm{h} / \mathrm{d}\end{array}$ & & & $\begin{array}{l}10 \% \\
\text { years }\end{array}$ & $\begin{array}{l}50 \% \\
\text { years }\end{array}$ & years & $\%$ \\
\hline Forest workers & 200 & & & & & & & & \\
\hline 1. chain saw generation & & 11 & $2-3$ & 9 & 19 & 3.3 & 7.5 & $<5$ & 40 \\
\hline " & & 2 & $3-5$ & 2 & 14 & 15.0 & 33 & $<10$ & 16 \\
\hline 3. & & 2 & 5 & 2.2 & 12 & 13.7 & 30.5 & $>10$ & $<7$ \\
\hline Pedestal grinders & 12 & & & & & & & & \\
\hline corundum wheel & & 15 & 7 & 20 & 18 & 1.3 & 3.2 & $>5$ & not known \\
\hline zirconium wheel & & 15 & 7 & 20 & 21 & 1.3 & 3.2 & $<1$ & 100 \\
\hline Shipyard workers & 171 & & & 7.5 & & 4.0 & 9.0 & 16 & 5 \\
\hline griding machine & & 2 & 2 & 1.5 & 12 & & & & \\
\hline scaling hammers & & 13 & 1 & 6.5 & 15 & & & & \\
\hline Stone workers & 16 & & & & & & & & \\
\hline pneumatic hammer & & 17 & 5.5 & 19 & 26 & 0.2 & 0.5 & 6 & 75 \\
\hline chisel head & & 110 & 5.5 & 130 & 22 & 1.6 & 3.5 & 9 & 50 \\
\hline Platers & 5 & 74 & 7 & 98 & 19 & 0.7 & 0.5 & 5 & 40 \\
\hline
\end{tabular}


when the observed latencies were clearly lower and prevalences higher than could be expected from the exposure data. The expected latencies were lower for shipyard workers, for stone workers and for platers.

\section{Discussion}

The standard method for the measurement and analysis of vibration transmitted to the hand is restricted to the measurements of frequency-weighted acceleration and daily exposure time. The method allows the evaluation of the latency period for vibration-induced white finger at probability levels of 10 to $50 \%$ (ISO 5349, 1986).

The present results demonstrate that the ISO method provides a good estimate of VWF for forest workers. However, the present results suggest that the ISO method may not be applicable for general risk assessment in different occupations. For pedestal grinders the method clearly underestimated the development of VWF. The present study showed opposite results for other groups and may emphasize the importance of individual or other workrelated factors in the genesis of VWF.

The hand grip forces can only be measured in the laboratory. Transmission of vibration is shown to be proportional to the cubic root of compression force (Pyykkö et al. 1976). New grinding machines were more effective and were supplied with harder grinding wheels than the old grinding machines. Work efficiency was increased by about 20-30\% compared to the old wheels and machines. The weighted acceleration was equal in both the wheels but the impulsiveness of vibration was shown to be clearly higher for the new wheels than for the old ones. Thus impulse vibration may be transmitted to the finger-palm area to a greater extent when cleaning castings with new wheels than with old wheels. The physiological effects of impulsive vibration are not clearly understood, but it has been suggested that they may create shock waves in tissues that contribute to the hazards by two different mechanisms. High impact waves may distort the tissues and even lead to leakages and capillary dilatations. Furthermore, impulsive vibration may spread to larger body areas and recruit more receptors and thereby contribute to the injuries caused by vibration (Pyykkö et al. 1982).

The ISO 5349 risk assessment method seemed to overestimate the hazards caused by vibration to shipyard workers. This may be due to the short operation periods which are distributed through the day. Moreover, the operation of hand-held power tools at the shipyard do not require such high hand grip forces as in pedestal grinding.

Discrepancies between expected and observed latencies and prevalences were also found in the hands of stone workers. They were exposed to extremely high asymmetric vibration. A corresponding difference between the left and right hands could not be found in the VWF data. This result emphasizes the importance of vibration transmission to the hand and arm.

The left hand of blade straighteners was exposed to very high level vibration impulses. Their contact with the blade was fairly flexible, since only the fingertips of the left hand were in contact with the blade.

The glove tested in the present study was chosen to represent a typical type of glove, commonly used at work places by operators of hand held power tools. The attenuation efficiency of the glove against vibration was shown to be poor and, in most cases, the exposure to vibration even seemed to be increased. This result was in agreement with previous studies (Pyykkö et al. 1976; Griffin, 1982). However, the 
effect was slight and dependent on the frequency in such a manner that a conclusive statement can not be given for either protection or amplification of vibration by the gloves.

The attenuation of vibrations in the head was about $10 \mathrm{~dB}$ more than that in a previous study from $20 \mathrm{~Hz}$ to $60 \mathrm{~Hz}$ (Sakakibara, 1986). The differences may be attributed to the measuring method, body posture and different hand-grip force. In the previous study the subjects kept the pulling force constant with the elbow joint stretched during the tests (Sakakibara, 1986). In the present study the subjects were sitting by the shaker with their upper arm $30^{\circ}$ below the horizontal level and the elbow joint at an angle of $120^{\circ}$. The position was selected to correspond to a usual body posture in the work environment. More through investigation is required on this point.

In a previous study (Dupuis et al. 1986), vibration stimulation at $7 \mathrm{~Hz}$ with two body postures, resulted in differences of approximately $100 \%$ in acceleration at the head, which increased further with increasing frequency. So, head measurements often cannot be compared, if different measuring sites have been chosen.

At most frequencies the coherence was sufficient for reliable FRF analysis. Also the repeated measurements for a test subject showed that the repeatability was satisfactory. The low coherence at distinct frequencies could be caused by absorption of energy in the human body and by the non-linearities in the hand-arm system. The extraneous noise in the measurements is not a probable explanation for the laboratory measurements (Bendat and Piersol, 1986).

The frequency response function is in dependent of the input signal in a linear system. However, it is dependent on work-related factors such as weight of the tool, static and dynamic forces during operation, contact surfaces between the source and hand, the position of the hand, and muscle load in the hand-arm area. Their role in the genesis of hazardous effects is obscure, but these results demonstrate the need to conduct further studies in this area.

\section{References}

Bendat, J. and Piersol, A.G. (1896). Random data, analysis and measurement procedures, 2nd Ed. New York:John Wiley \& Sons.

Dubuis, H. and ZerLett, G. (1986). The Effect of Whole Body Vibration. Berlin, Heidelberg, New York, Tokyo: Springer-Verlag.

Färkilë̈, M., Starck, J. and Hyvärinen, K. (1978). Vasospastic symptoms caused by asymmetrical vibration exposure of upper extremities to a pneumatic hammer. Scand J. Work Environ. Health 4, 330-335.

Griffin, M. J. (1982). Hand-arm vibration standards and dose effect relationship. In Vibration Effects on the Hand Arm in Industry, Brammer, A. J., Taylor, W., eds. pp. 259-268. New York: John Wiley and Sons.

IEC Standard 651 (1979). Sound level meters. International Electrotechnical Commission. Geneve, p. 53.

ISO 5349 (1986). Guidelines for the measurement and the assessment of human exposure to hand transmitted vibration. International Organization for Standardization, Geneva, p. 13.

Manninen, O. and Еквlom, A. (1984). Single and joint actions of noise and sinusoidal whole body vibration on TTSs values and low frequency upright posture sway in men. Int. Arch. Occup. Environ. Health 54 1-17.

NEREM, R. M. (1973). Vibration-induced arterial shear stress: The relationship to Raynaud's phenomenon of occupational origin. Arch. Environ. Health 26, 105-110.

Okada, A., Miyahe, H., Yamamma, K. and Minamin, M. (1972). Temporary hearing loss induced by noise and vibration. J. Acoust. Soc. Am. 51, 1240-1248.

Perkarinen, J. and Starck, J. (1986). Digital high-speed sampling of combined exposure to noise and vibration. Scand. J. Work Environ. Health 12, 327-331.

PyykKö, I., FÄrkKill̈, M., Tolvanen, J., Korhonen, 
O. and HyVÄrinen, J. (1976). Transmission of vibration in the hand-arm system with special reference to changes in compression force and acceleration. Scand. J. Work Environ. Health 2, 88-95.

Pyykkö, I., Hyvärinen, J. and FärkKilä, M. (1982). Studies on the etiology mechanism of the vasospastic component of vibration syndrome. In Vibration Effects of the Hand Arm in Industry, eds. Brammer, A. J., Taylor, $\mathrm{W}, \mathrm{pp}$. 13-24. New York: John Wiley \& Sons.

Pyykkö, I., Korhonen, O., Färkkilä, M., Starck, J., Aatola, S. and JÄntTI, V. (1986). Vibration syndrome among Finnish forest workers, a follow-up study from 1972 to 1983 . Scand. J. Work Environ. Health 12, 307-312.

Rens, G., Dubrulle, P. and Malchane, J. (1987). Efficiency of conventional gloves against vibration. Ann. Occup. Hyg. 21, 249-254.

Sakakibara, H., Takeiaki, K., Masaru, M., Shin'ya, Y., Takeo, N., Kobayashi, F. and Ono, Y. (1986). Transmission of hand-arm vibration to the hand. Scand. J. Work Environ. Health 12,
359-361.

Starck, J., Färkkilä, M., Aatola, S., Pyykkö, I. and Korhonen, O. (1983). Vibration syndrome and vibration in pedestal grinding. $\mathrm{Br}$. J. Ind. Med. 40, 426-433.

Starck, J. (1984). Characteristics of vibration, hand grip force and hearing loss in vibration syndrome. Publications of the University of Kuopio, Natural Sciencies, Original Report 4, Kuopio, p. 64.

Starck, J. (1984). High impulse acceleration levels in hand-held vibratory tools. An additional factor in the hazards associated with the hand-arm vibration syndrome. Scand. J. Work Environ. Health 10, 171-178.

Starck, J., Pekrarinen, J. and Pyykкö, I. (1988). Impulse noise and hand-arm vibration in relation to sensory neural loss. Scand. J. Work Environ. Health 14, 265-271.

TAYLOR, W. (1974). Introduction. In The Vibration Syndrome, ed. Taylor, W. pp. 1-12. London: Academic Press. 